\title{
Safety variability assessment of reinforced concrete beams subjected to bending moment considering the NBR 6118:2014 safety partial factors
}

\section{Avaliação da variabilidade da segurança de vigas em concreto armado submetidas ao momento fletor considerando os coeficientes parciais de segurança da NBR 6118:2014}
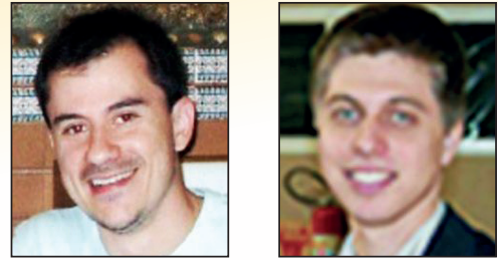

C. G. NOGUEIRA cgnogueira@feb.unesp.br

M. D. T. PINTO a matheus.debianchi@gmail.com

\begin{abstract}
This paper presents a study about safety of reinforced concrete beams subjected to bending moment and designed with the partial safety factors proposed by ABNT NBR 6118:2014. The main goal was to assess the uniformity in the safety of the beams considering different values for the neutral axis position and the load ratio, by using the Reliability Theory. A simplified procedure to calibrate the partial safety factors was proposed taking into account the nature of each random variable and a target reliability index. From the analysis of the results, an alternative method for the design of reinforced concrete beams was also proposed, in which safety is guaranteed by the using of a probability of failure instead a set of partial safety factors. The results showed the lack of uniformity in the safety of the beams design with de constant set of partial safety factors. The procedures of design and calibration of the new safety factors were capable of to give uniformity to the safety of the beams and to achieve the proper structural configuration with the required safety level.
\end{abstract}

Keywords: reinforced concrete structures, partial safety factors, reliability, calibration.

\section{Resumo}

Este artigo apresenta um estudo sobre a segurança de vigas em concreto armado solicitadas por momento fletor dimensionadas com os coeficientes parciais de segurança da ABNT NBR 6118:2014. O principal objetivo foi avaliar a uniformidade na segurança das vigas para diferentes posições da linha neutra e razão de carregamentos, com o uso da Teoria da Confiabilidade. Um procedimento simplificado para a calibração dos coeficientes parciais de segurança foi proposto, levando-se em conta a natureza de cada variável aleatória e um valor alvo para o índice de confiabilidade. A partir desses resultados, um método alternativo para o dimensionamento à flexão das vigas foi também proposto, no qual a segurança é verificada através de uma probabilidade de falha e não mais por coeficientes parciais. Os resultados mostraram a falta de uniformidade na segurança das vigas quando dimensionados com o conjunto fixo de coeficientes parciais. Os processos de calibração e dimensionamento alternativos mostraram-se capazes de uniformizar a segurança e ainda obter a configuração estrutural que apresenta o nível de segurança requerido.

Palavras-chave: estruturas de concreto armado, coeficientes parciais de segurança, confiabilidade, calibração.

Universidade Estadual Paulista, Faculdade de Engenharia, Departamento de Engenharia Civil, Bauru - SP, Brasil. 


\section{Introduction}

The design of structures can be understood as an iterative process that seeks to establish dimensions and configurations to the constituent elements of the structural system, in which a set of bounds is respected to guarantee the requirements of security, economic, aesthetic, functionality and durability. Within this context, the standard design codes represent a fundamental role in the process, because they are the instruments that define this acceptable limits set that ensure the performance requirements of the structural system. Regarding to the safety of the structure, the current codes are based on the Limit State Design which has to ensure for the different behaviors (limit states) governing the structural system the following condition: $R_{d} \geq S_{d}$. In other words, the design value of the resistance $\left(R_{d}\right)$ must always be greater than or equal to the design solicitation $\left(\mathrm{S}_{\mathrm{d}}\right)$. In each considered limit state, each of these portions depends on various parameters, such as: dimensions of the cross sections, resistance of materials, quantities of steel reinforcement, positions of these reinforcements and internal efforts among others.

In the development of a project, after the design of the structural system, the next step is to quantify the acting loads on the structure and specify the materials used for the construction of structural elements, as well as its mechanical properties. However, there are uncertainties arising from the very nature of each parameter, as well as the procedures for obtaining the materials, use of construction, construction techniques, methods of analysis and variations in loads that, and if not handled properly, can lead to an excessive risk, compromising the safety and/or the use of the buildings in an extreme situation. To consider the presence of uncertainties, the current design codes adopt the so-called safety partial factors. Such factors affect the loads increasing its effects and reducing the resistance of the material. So, after application of the safety factors, resistance and solicitation (reason the index "d" in R and S shown above) for each limit state considered in the project are obtained. In fact, with this procedure, it originates a safety margin regarding to the magnitude of these adopted safety partial factors. In general, the greater these factors are, the greater the safety margin and hence greater the limit state safety level. This approach improves the quantification of structures performance because considers, in a more rational way, the uncertainties inherent to the design parameters and requires the explicit evaluation of security conditions for both situations: on service and to extreme states that indicate possible individual ruptures and/or the system as a whole (Ellingwood and Galambos [1]).

The safety factors, for many years, were determined according to the experience and judgment of professional manufacturers and even improved from accidents and disasters of buildings, showing the construction process of trial and error. It was only from the end of the 18th century that the first structural calculations were recognized, being credited to Coulomb and Navier, while only at the end of the 20th century, advances in concepts and methods of structural analysis, accompanied by the development and diffusion of computers, allowed to better understand the behavior of structures, enabling significant improvements in engineering projects (Ellingwood [2]). However, the uncertainties inherent in loading and material properties remained, so that, thanks to these uncertainties, the risks arise on the structural projects, giving rise to occurrence of adverse events. The consequences in these cases can bring serious damage in terms of loss of human life and in economic aspects to the society. To avoid these types of events, the current design codes adopt again the safety partial factors to ensure that the behavior of the systems and the risks associated with projects remain within acceptable limits for the whole society. Given this, there are questions such as: a) if even with the use of safety factor there are still risks, how safe are currently designed structures? b) or, which is the "distance" in terms of security between a service status and a possible situation of failure to a certain limit state? In addition, before the advances in materials technology, methods of numerical analysis and also fewer resources available for the construction of buildings, there is a need to improve the behavior prediction of structural systems, as well as to assess more consistently the safety of these structures. Thus, the definition of the safety partial factors based on experience and professional judgment is no longer justified, which introduce the need to calibrate these coefficients more rationally.

During the last decades, design codes based on the limit state method have calibrated the partial safety coefficients from probabilistic approaches. There are several criteria to perform the calibration process of these coefficients, so that resulting in a set of values that cover all structures belonging to a certain class, defined in the scope of the code [3-5]. The Reliability Theory has been used for such task, once the stochastic nature of the risks, accidental loads and material properties make evident the need of probabilistic treatment for coefficients calibration [2 and 6]. The great advantage of this approach is that the limit state method with calibrated safety coefficients based on probabilistic procedures, has transformed the classical integral that defines the problem of structural reliability [7] in a practical and direct way for use in projects, even for professionals who are not familiar with the concepts of the Reliability Theory.

However, the design codes adopt a fixed set of partial safety factors that are applied to all structures present in the implementation scope of the code. This assumption makes that different types of structural elements designed with such coefficients do not have uniform safety levels for the various limit states. This approach tends to generate structural systems with reliability greater than minimum amounts required, oversizing structures. On the other hand, it is possible that the adoption of constants safety factors generates structures with global reliability lower than the recommended minimum values, which is clearly against the security situations [8-9]. In this context, Mohamed et al. [9] highlighted the lack of uniformity in the safety of pillars in reinforced concrete designed with partial factors proposed by Eurocode 2, considering variations in important parameters like slenderness index, concrete resistance, axial load eccentricity and longitudinal steel reinforcement. After confirmation of lack of uniformity, a method was proposed for calibration of the coefficients on the basis of a uniform reliability level. Castillo et al. [10] presented a design methodology of reliability based optimization in which reliability constraints were incorporated into the formulation of the optimization problem. Thus, the safety partial factors applied to the used random variables were calibrated so that the designed structure present uniform reliability and minimum cost. The process was carried out considering the simultaneous occurrence of more than one failure mode in the design of a bridge crane beam. The authors found that in these cases the optimized 
design makes active one or more reliability constraints, calibrating the partial factors for these restrictions, but let the other restrictions remain inactive exceeding the amount required for security in those restrictions. It is important to note that the same reliability target can produce several solutions that correspond to different combinations of partial factors, once the calibration process can be accomplished in several ways. A criterion to guide the choice of the best set of coefficients may be adopted as the one that generates the minimum cost structure (Gayton et al. [11]).

Stucchi and Santos [12] made a study on the design philosophy adopted in the Brazilian standards NBR 6118 [13] and North American ACl 318-05 [14], comparing the reliability obtained for beams and slabs designed with both codes. Although the way to consideration of safety factor is different in both codes, the safety level obtained with each of them can be compared for reliability analysis. The authors also concluded that both design codes do not provide uniformity of safety in terms of the reliability index. However, the $\mathrm{ACl}$ showed better uniformity than the Brazilian standard, considering various criteria of load combinations for the design of structural elements, while the Brazilian standard uses only one combination for live and dead loads.

Once detected the deficiency of design codes to provide uniform security for structures inserted in their categories, a current alternative is to attempt to propose calibration methods of partial factors, in order to generate more uniform safety level. Beck and Souza Jr. [15] proposed a calibration procedure for the safety partial factors of the Brazilian standards NBR 8800 [16] and American ANSI / AISC [17], from the solution of an optimization problem written in terms of the reliability indices obtained for structural elements compared with required values. Several loading ratios were tested between live and dead loads, as well as between wind and dead loads. The results showed that the new set of partial factors resulted in greater uniformity of the elements designed with both codes. In this context, the main purpose of this paper is to evaluate the uniformity (or lack thereof) of the safety of reinforced concrete beams designed according to the criteria of NBR 6118 [13] considering the proposed safety partial factors and the variation of the relative position of the neutral axis and the active load ratios. Then, a process of safety partial factors calibration was proposed in order to standardize the safety of beams for the ultimate limit state of loss of load capacity to bending moment and, therefore, an alternative design procedure of beams using reliability was performed and compared with the current procedure.

\section{Flexural resistance of reinforced concrete beams}

The resistance of reinforced concrete beams of rectangular crosssection to the bending moment comes from the classical equations of equilibrium ( $\Sigma \mathrm{N}=0$ and $\Sigma \mathrm{M}=0$ ) and of the provisions recommended by the NBR 6118 [13]. Figure 1 shows the configuration used to assess the resistance to bending moment in rectangular beams with simple reinforcement for values of $f_{c k} \leq 50 \mathrm{MPa}$.

The internal resistant bending moment referent to the compressed concrete $\left(M_{R c c}\right)$ and tensioned reinforcement $\left(M_{R s t}\right)$, as well as the bending moment resistance of the cross-section $\left(M_{R}\right)$ are given respectively by:

$$
M_{R c c}=R_{c c} z_{c c}=M_{R s t}=R_{s t} z_{c c}
$$

$$
M_{R c c}=0,68 b_{w} x f_{c d}(d-0,4 x)
$$

$$
M_{R s t}=\sigma_{s d} A_{s}(d-0,4 x)
$$

\section{Figure 1 - Stress and strain distribution in RC beams with rectangular cross section and tension reinforcement at the imminence of the rupture}

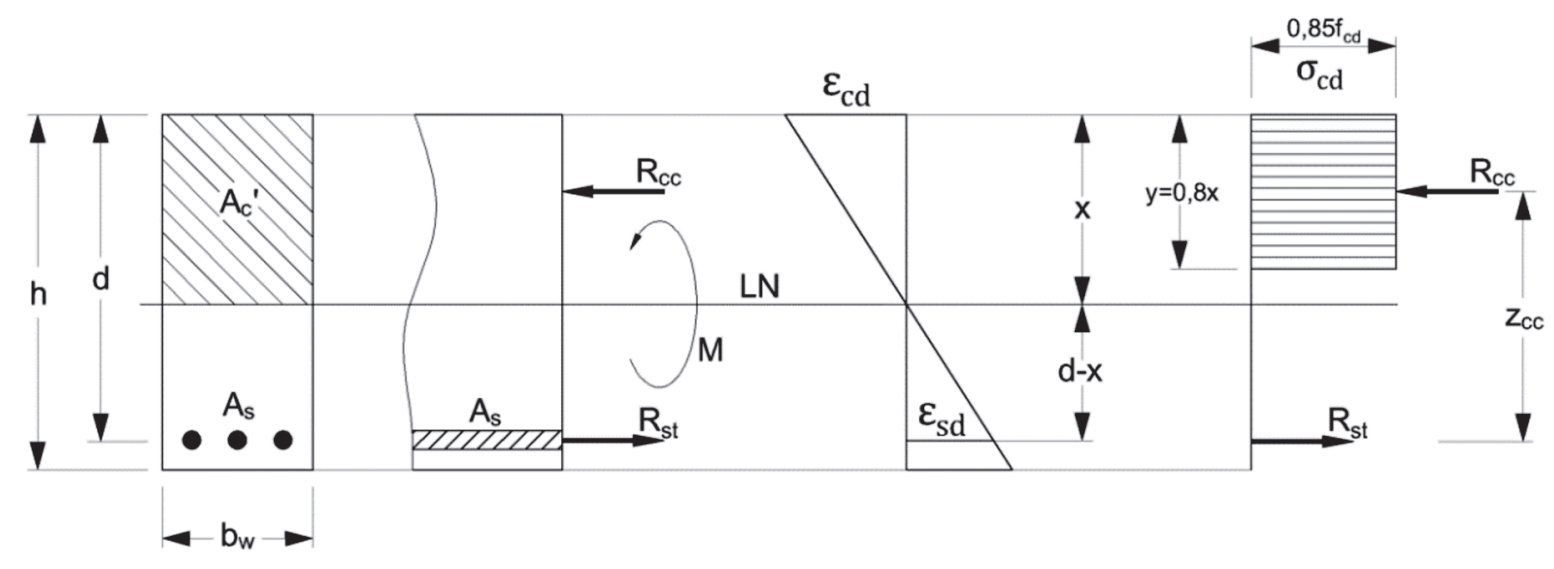




$$
M_{R}=M_{R c c}=M_{R s t}
$$

Replacing the position of the neutral axis $(x)$ by the dimensionless relative value $\left(\beta_{x}=x / d\right)$ in Equations (2) and (3) we have:

$$
M_{R c c}=0,68 b_{w} \beta_{x} d^{2} f_{c d}\left(1-0,4 \beta_{x}\right)
$$

$$
M_{R s t}=\sigma_{s d} A_{s} d\left(1-0,4 \beta_{x}\right)
$$

In the ultimate limit state, the moment resistance must be greater than or equal to the solicitation moment $\left(M_{d}\right)$, which determines the reinforcement area necessary for the beam as:

$$
A_{s}=\frac{M_{d}}{\sigma_{s d} d\left(1-0,4 \beta_{x}\right)}
$$

The equilibrium equation in terms of horizontal forces $(\Sigma N=0 \rightarrow$ $\mathrm{R}_{\mathrm{cc}}-\mathrm{R}_{\mathrm{st}}=0$ ) is given by:

$$
0,68 b_{w} d \beta_{x} f_{c d}-\sigma_{s d} A_{s}=0
$$

Where: $b_{w}$ is the cross section width; $f_{c d}$ is the design value for concrete compressive strength given by $f_{c k}$ (characteristic value of concrete compressive strength) reduced by the safety partial factor $\gamma_{c}=1,4 ; \sigma_{s d}$ is the normal stress in the tensioned reinforcement, which depends on the neutral axis position. In cases of the deformation domains 2 and 3 , which are the more usual situations where the beams are dimensioned to bending moment, the steel is already in yielding. So $\sigma_{s d}$ can be replaced by $f_{y k}$ (characteristic value of the steel yield stress) divided by the safety partial factor $\gamma_{\mathrm{s}}=1,15$.

The equation 5 , which is the result of the balance of moments in the cross section $(\Sigma M=0)$, can only be applied from the prior knowledge of the cross section height (d) and the relative neutral axis position $\left(\beta_{x}\right)$. Therefore, the design is finalized by adopting one of these variables and then applying the balance of the horizontal forces (Equation 8 ) to determine the other unknown variable. Both cases are quite used, the height of the beams can be adopted previously in function of the pre-design or of architectural constraints of the project, as well as the neutral axis position can be set on the basis of normative criteria (ductility) and compatibility of deformations. It is worth to mention that this description was not considered compression reinforcement.
Thus, it can be verified that there are a variety of possible solutions for the cross section of the beams, as they adopt different values for the neutral axis position, even keeping the safety partial factors and the original height.

\section{Reliability theory and methods of analysis}

In general, the main purpose of the structural reliability analysis is related to the probabilities determination of occurrence of scenarios of interest related to the problem under study. More specifically, according to the several uncertainties inherent in the design parameters of the structural system, as well as the structural analysis processes and even constructive methods, there will always be a probability of violation of one or more limit states which define system behavior. Thus, the failure probability can be defined as a violation of a limit state. In this context, the limit states are represented by mathematical functions described from deterministic and random parameters, setting a boundary between the security and failure regions in the field of the problem possibilities. Mathematically it can be expressed by:

$$
G(X, U)=f\left(x_{1}, x_{2}, \ldots, x_{n}, U\right)
$$

Where: $X$ is the set of random variables; $U$ is the set of deterministic parameters. When $G=0$ one has the definition of the event that causes the limit state.

Thus, each realization of the random set of system parameters that violates the limit state function is considered as a point in the failure domain of the problem. Let $R$ is taken as a resistance random variable and $S$ defined as a solicitation random variable, both being dependent on $X$ and $U$, one of the ways to write Equation (9) can be given by $G=R-S$. The failure probability $\left(P_{f}\right)$ can then be defined as the probability of $G<0$ and written by:

$$
P_{f}=P(R-S \leq 0)=\iint_{-\infty-\infty}^{+\infty} \int_{R S}^{s}(r, s) d r d s
$$

Where: $f_{R S}$ is the joint probability density function of the variables $R$ and $S ; r$ and $S$ are the assumed values for $R$ and $S$ from each of the realization of the parameters of $X$ and $U$.

However, the direct evaluation of failure probability by Equation (10) in practical terms is very complicated, since there is no known information about the joint probability density function of the random variables. To resolve this issue, several alternative methods have been developed to determine the failure probability, where we can mention the FORM, SORM, Response Surface Method and Monte Carlo Simulation Method among others.

Santos et al. [22] classify alternative methods to solve the problem as: fully probabilistic, because they consider the combined distribution with all the random variables (Monte Carlo Simulation); fully with probabilistic approaches, where the failure probability is assessed from the association to the reliability index $(\beta)$ given by $P_{f} \approx$ $\Phi(-\beta)$, in which $\Phi($.$) as the inverse cumulative distribution function$ 
Table 1 - The adopted random variables on the problem

\begin{tabular}{|ccccc}
\hline Random variable & Mean & C.O.V. & Probability distribution & Reference \\
\hline $\mathrm{f}_{\mathrm{c}}(\mathrm{MPa})$ & 25 & $12 \%$ & Lognormal & Mohamed et al. (2001) \\
$\mathrm{f}_{\mathrm{y}}(\mathrm{MPa})$ & 550 & $6 \%$ & Lognormal & Mohamed et al. (2001) \\
$\mathrm{M}_{\mathrm{g}}(\mathrm{kNcm})$ & $1,05 \times \mathrm{M}_{\mathrm{ng}}$ & $10 \%$ & Normal & Ellingwood et al. (2001) \\
$\mathrm{M}_{\mathrm{q}}(\mathrm{kNcm})$ & $1,00 \times \mathrm{M}_{\mathrm{nq}}$ & $25 \%$ & Gumbel extrem type I & Ellingwood et al. (2001) \\
\hline
\end{tabular}

in the standard normal space (FORM, SORM). More details about the methods can be found in Nowak and Collins [4].

\section{Formulation of the problem before calibration}

The initial problem before the calibration proposal of the safety partial factors was formulated from the possibility of obtaining several different solutions to the same beam depending on the neutral axis position in cross section. In addition, in order to verify the influence of the live loads on the safety of the beams, it was considered a set of load ratios $(R)$ as defined by the ratio between the nominal bending moments from the live loads $\left(M_{n q}\right)$ and dead loads $\left(M_{n g}\right)$. The following values for the relative neutral axis position were: 0,$167 ; 0,200 ; 0,231 ; 0,259 ; 0,280 ; 0,304 ; 0,333 ; 0,412 ; 0,466$; 0,$500 ; 0,538 ; 0,608$ and 0,628 . Similarly, the load ratios assumed the following values: 0,$1 ; 0,3 ; 0,5 ; 0,7 ; 0,9 ; 1,1 ; 1,3$ e 1,5 . The concrete and steel resistance values were kept constant in the study with $\mathrm{f}_{\mathrm{ck}}=20 \mathrm{MPa}$ and $\mathrm{f}_{\mathrm{yk}}=500 \mathrm{MPa}$, respectively.

In the first step, the reinforced concrete beams were design to bending moment considering constant values for the cross-section's width of $14 \mathrm{~cm}$ and effective depth of $45 \mathrm{~cm}$ (overall thickness of $50 \mathrm{~cm}$ ). The safety partial factors were kept the same as recommended by NBR 6118 [13], i.e. $\gamma_{c}=1,4$ and $\gamma_{s}=1,15$. Given these parameters and each value for the relative position of the neutral axis, the tension reinforcement area was dimensioned from Equation (8). With the tensioned reinforcement values, the bending moment resistance of the cross section was obtained for each neutral axis position by Equation (6).

Then, the reliability analyzes were performed for the different designed cross-sections in the previous step. In this step, the requesting bending moments were defined from the moment resistance of the beam, as:

$$
M_{R}=\gamma_{g} M_{n g}+\gamma_{q} M_{n q}
$$

Where: $M_{R}$ is the bending moment resistance of the cross section, which is, in the design condition, equal to the total requesting bending moment; $M_{n g}$ and $M_{n q}$ are respectively the requesting nominal bending moments relating to dead and live loads; $\gamma_{g}$ and $\gamma_{q}$ are respectively the safety partial factors that provide security for dead and live bending moments, both adopted as 1,4.

Once the load ratio is given by $R=M_{n q} / M_{n g}$ and was varied from 0,1 to 1,5 as previously described, the solicitation values were ob- tained as:

$M_{R}=\gamma_{g} M_{n g}+\gamma_{q} R M_{n g}=$
$M_{n g}\left(\gamma_{g}+\gamma_{q} R\right) \rightarrow M_{n g}=\frac{M_{R}}{\left(\gamma_{g}+\gamma_{q} R\right)}$
$M_{n q}=R M_{n g}$

The random variables considered in the study were: compressive strength of the concrete $\left(f_{c}\right)$, strength of the steel $\left(f_{y}\right)$, dead bending moment $\left(\mathrm{M}_{\mathrm{g}}\right)$ and live bending moment $\left(\mathrm{M}_{\mathrm{q}}\right)$. Table 1 shows the statistics associated with the variables in order to take into account the uncertainties.

The limit state equation that represents the safety of reinforced concrete beams is given by:

$G=M_{R}-M_{g}-M_{q}$
$M_{R}=0,408 b_{w} f_{c} d^{2} \beta_{x}^{2}+A_{s} f_{y} d\left(1-\beta_{x}\right)$

The reliability analyzes were performed considering the FORM with direct coupling, in which the derivatives of $G$ are evaluated implicitly by finite differences. The convergence in the search process was written in terms of failure probability and design point with an error tolerance of $10^{-4}$.

\section{Results before calibration}

Table 2 illustrates the averages of random variables, considering each of the load ratios as well as the reliability indices $(\beta)$ obtained in the analysis. All these results refer to a single value of the relative position of the neutral axis. This process was repeated for all other values of $\beta_{x}$, leading to 104 analyzes in total.

Figure 2 shows the results of the beams analyzes in terms of 
Table 2 - Results in terms of reliability index for $\beta_{x}=0,167$

\begin{tabular}{|c|c|c|c|c|c|c|}
\hline $\mathrm{f}_{\mathrm{ck}}(\mathrm{MPa})$ & $\mathbf{R}$ & $f_{c, \text { mean }}(M P a)$ & $\mathrm{f}_{\mathrm{y} \text {, mean }}(\mathrm{MPa})$ & $M_{g \text { mean }}(\mathrm{kNcm})$ & $M_{q, \text { mean }}(\mathrm{kNcm})$ & $\beta$ \\
\hline \multirow{8}{*}{20} & 0,1 & \multirow{8}{*}{25} & \multirow{8}{*}{550} & 2926,3 & 278,7 & 6,04 \\
\hline & 0,3 & & & 2476,1 & 707,5 & 4,98 \\
\hline & 0,5 & & & 2146,0 & 1021,9 & 4,28 \\
\hline & 0,7 & & & 1893,5 & 1262,3 & 3,88 \\
\hline & 0,9 & & & 1694,2 & 1452,2 & 3,62 \\
\hline & 1,1 & & & 1532,8 & 1605,8 & 3,44 \\
\hline & 1,3 & & & 1399,6 & 1732,8 & 3,31 \\
\hline & 1,5 & & & 1287,6 & 1839,4 & 3,21 \\
\hline
\end{tabular}

variability of the reliability index considering the different neutral axis positions for all load ratios. The horizontal line represents the target value of $\beta=3,8$ recommended by Eurocode 2 [20] to the ultimate limit state. The vertical lines contain the results for all values of $\mathrm{R}$ for the same neutral axis position, in which the top points are referred to $R=0,1$ while the bottom points represent $R=1,5$.

Considering all the possibilities for the neutral axis position in the same cross section and the several load ratios, the reliability index resulted from $\beta_{\min }=3,21$ and $\beta_{\max }=6,72$ reflecting in failure probabilities $P_{f, \text { min }}=8,89 \times 10^{-12}$ and $P_{f, \text { max }}=6,64 \times 10^{-4}$. This large difference shows the lack of uniformity in the safety of the beams designed with the fixed set of partial safety factors. Furthermore, it was found that in some cases the reliability index resulted lower than the limit values recommended by Eurocode 2, which is clearly a design situation against the safety. The design situations with higher values of $R$, in the case where the live portion of moment increases in relation to the dead moment resulted in lower rates of reliability when compared to beams designed for lower load ratios. This is consistent because the uncertainties present in quantifying live loads are significantly higher than those observed in the dead loads, which results in less structural safety. Similarly, as the overall thickness of the beams was always kept constant, larger values of $\beta_{x}$ also resulted in larger values of resistant bending moments, which suggest an increase in the bending resistance of the beam, since the amount of longitudinal reinforcement increases. Therefore, for situations where the overall thickness of the beams is limited by architectural issues and kept constant, higher values in the neutral axis provide larger values for the resistant bending moment. However, it is worth to mention in such cases, the failure may occur by the concrete crushing on the top fibers of the cross section. This condition must always be avoided in the design of reinforced concrete beams because it changes the behavior of the beams from ductile to brittle resulting in a very dangerous situation in designing. For such reason, the NBR 6118 [13] restricts the relative neutral axis position as a function of the concrete compressive strength in order to avoid structures with a brittle behavior and high amounts of longitudinal reinforcement.

The average values for the reliability index for each of the neutral axis position resulted, in general, between 4,0 and 5,0 . This means that, on average, the design of reinforced concrete beams considering the safety partial factors of NBR 6118 [13] is acceptable and yet not so distant from the target value of $\beta=3,8$.
In Figure 3 it was represented the evolution of reliability index for some values of the relative neutral axis position depending on the load ratio. It was observed as the effect of live load increases on the structural behavior, the safety level of the beams decreases. In this case, as the depth of the cross section was kept constant, higher values of $\beta_{x}$ result in greater safety to the bending moment. Considering $\beta_{x}=0,500$, it was verified that only values of $R \geq 1,1$ the obtained $\beta$ was less than 3,8 . For load ratios between 0,3 and 0,7 which match the many of the usual situations in practice in reinforced concrete structures, the reliability index resulted between the values 4.0 and 5.0 as already noted. This shows that for beams designed in the domain 3 of deformation, the safety against bending moment is assured.

However, it is worth to note that due to the lack of uniformity observed, the use of fixed set of partial factors can lead to design structures against security. On the other hand, it is also possible that the designed beams present an excessive safety level, such as observed in cases where the live loads are very small when compared to dead loads. In such cases, it is clearly observed that

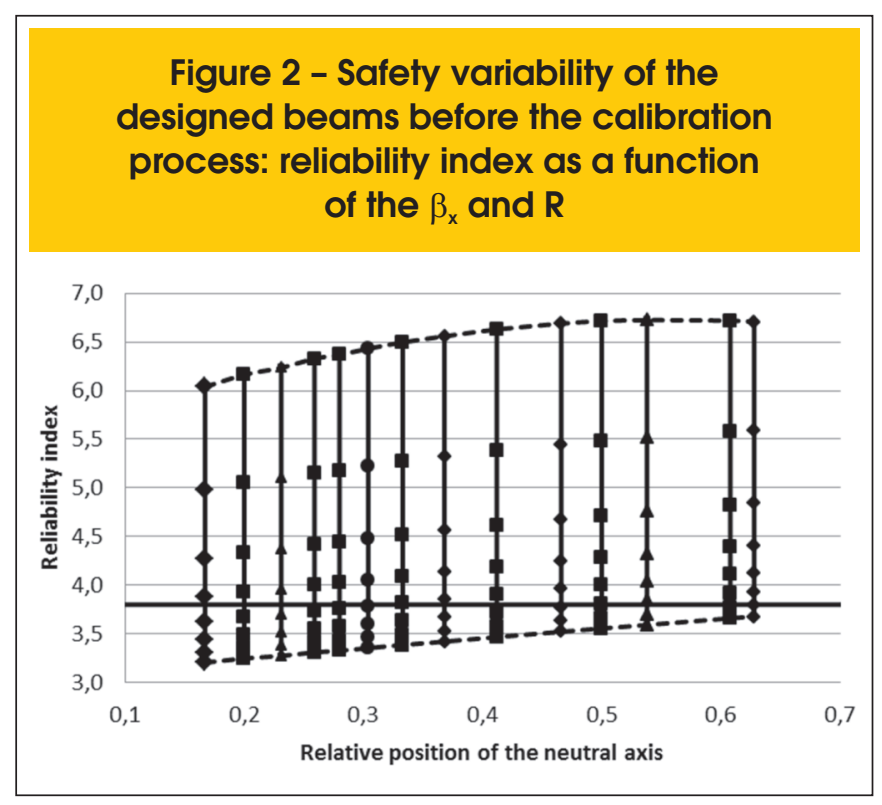




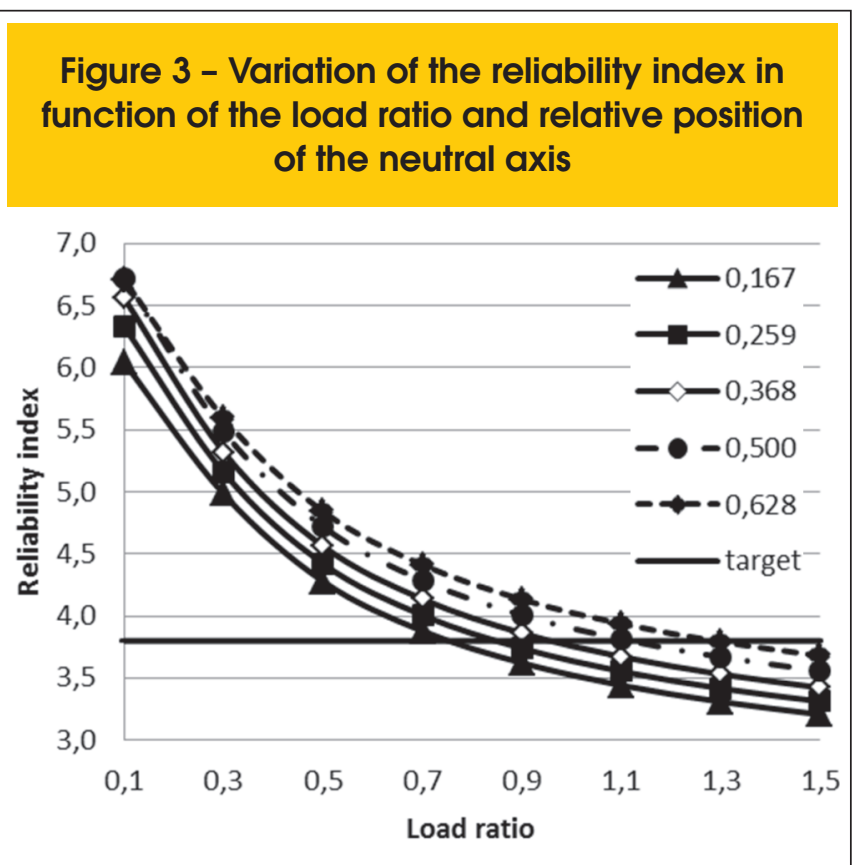

structures result oversized and at the same time anti-economical. Another result that deserves to be discussed is the sensitivity of random variables and its evolution over the parametric analysis. Figure 4 illustrates the average sensibilities of the variables obtained considering all the load ratios for some relative position of the neutral axis. As no ductility constraint was imposed in the analysis, it was observed that the importance of concrete resistance increases as the position of the neutral axis also increases. On the other hand, the resistance of steel suffers the reverse process. As the position of the neutral axis increases, the portion of the concrete in bending moment also increases, while the portion of reinforcement decreases, as can be seen in equation (15). Regarding to the requesting bending moments, the portion of variable moment is much more influen-

\section{Figure 4 - Variation on the random variables sensitivity regarding to failure probability of the beams before calibration}

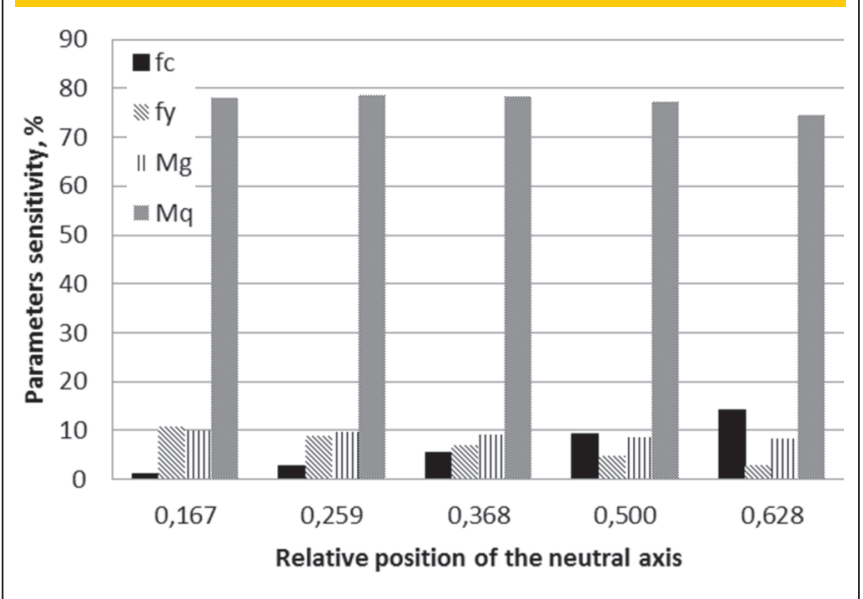

tial than the portion of the permanent bending moment. This behavior becomes more evident, as the load ratios $\mathrm{R}$ increases.

\section{Formulation of the problem for calibration}

In order to obtain more uniform safety levels in the design of reinforced concrete beams subjected to bending moment, it was performed a calibration procedure of safety partial factors of the random variables based on the procedure proposed by Mohamed et al. [9]. In general, the partial safety factors acting as resistance reducers $\left(\gamma_{R}\right)$ or increasers $\left(\gamma_{S}\right)$ of the load effects can be written as:

$\gamma_{R}=\frac{X_{k}}{X_{d}}$
$\gamma_{f}=\frac{X_{d}}{X_{k}}$

Where: $X_{k}$ and $X_{d}$ are, respectively, the characteristic values and design values of the considered parameters.

In case of the characteristic values, these are obtained from the quantile, which ensure that the overcoming of such values is very unlikely (in general, it allows to $5 \%$ quantile value). As for the design values, these are defined by the reliability analysis, in which the coordinate of the design point related to the analyzed variable $\left(X^{*}\right)$ is given in the standard normal space by:

$$
X_{d}=X^{*}=-\alpha_{X} \beta
$$

Where: $\alpha_{x}$ corresponds to the cosine director of the random variable $X ; \beta$ is the reliability index obtained in the iteration.

According to Mohamed et al. [9], the characteristic value of a variable, regardless of the probability distribution can be written in function of the average $\left(\mu_{x}\right)$ and the standard deviation $\left(\sigma_{x}\right)$ in the form: $\mathrm{X}_{\mathrm{k}}=\mu_{\mathrm{x}} \pm \delta \sigma_{\mathrm{x}}$, where $\delta$ expresses the probability (confidence level) that the $X_{k}$ value is exceeded. In the case of compression strength of the concrete, assuming normal distribution and the probabilities of $5 \%$ quantile for setting the characteristic value, $\delta$ takes on a value of 1,645. For the other probability distributions, $\mathrm{X}_{\mathrm{k}}$ can be given generally by:

$$
P\left[X>X_{k}\right](\text { variável resistência }) \rightarrow X_{k}=F_{X}^{-1}(1-p)
$$

$$
P\left[X<X_{k}\right](\text { variável solicitação }) \rightarrow X_{k}=F_{X}^{-1}(p)
$$


Where: $\mathrm{F}_{\mathrm{X}}^{-1}$ is the inverse of the cumulative probability distribution of the random variable; $X$ is the current value of the random variable; $p$ corresponds to the level of confidence which defines the required probability for the variable violates the characteristic value. In the case of a resistance variable and $5 \%$ confidence level, the probability that the value considered to overcome resistance $X_{k}$ is $95 \%$. On the other hand, for a solicitation variable with the same level of confidence, in just $5 \%$ of the time the value considered can overcome $X_{k}$. Therefore, the equations (16) and (17) can be rewritten, respectively, as:

$$
\gamma_{R}=\frac{X_{k}}{X_{d}}=\frac{F_{X}^{-1}(1-p)}{F_{X}^{-1}\left[\Phi\left(-\alpha_{X} \beta\right)\right]}
$$

$$
\gamma_{f}=\frac{X_{d}}{X_{k}}=\frac{F_{X}^{-1}\left[\Phi\left(-\alpha_{X} \beta\right)\right]}{F_{X}^{-1}(p)}
$$

Where: $\Phi$ is the standard normal cumulative probability function. The adopted hypothesis for the safety partial factors calibration consists in choose a target value for the reliability index and admit that the cosines directors of the random variables are kept constant. With that, the origin of standard normal system is moved so that the distance from the origin to the design point is equal to the target reliability index (Figure 5). For the calibration process, the target reliability index was 3,8 recommended by Eurocode 2 [20] to ultimate limit states. The used cosines directors of random variables were obtained by the reliability analysis, via FORM, performed in the previous step, i.e., during the safety evaluation of the beams before calibration.

In order to verify all the possibilities in the calibration process, the safety partial factors were obtained considering all the values of the relative position of the neutral axis for each load ratio. Thus, there were 104 calibrations of partial factors covering all cases intended for the beams design.

\section{Results after calibration}

Table 3 shows the results obtained with the calibration process, in terms of the new safety partial factors, the design point coordi-

\section{Figure 5 - Adopted hypothesis to safety partial factors calibration: the director cosines are kept constant}

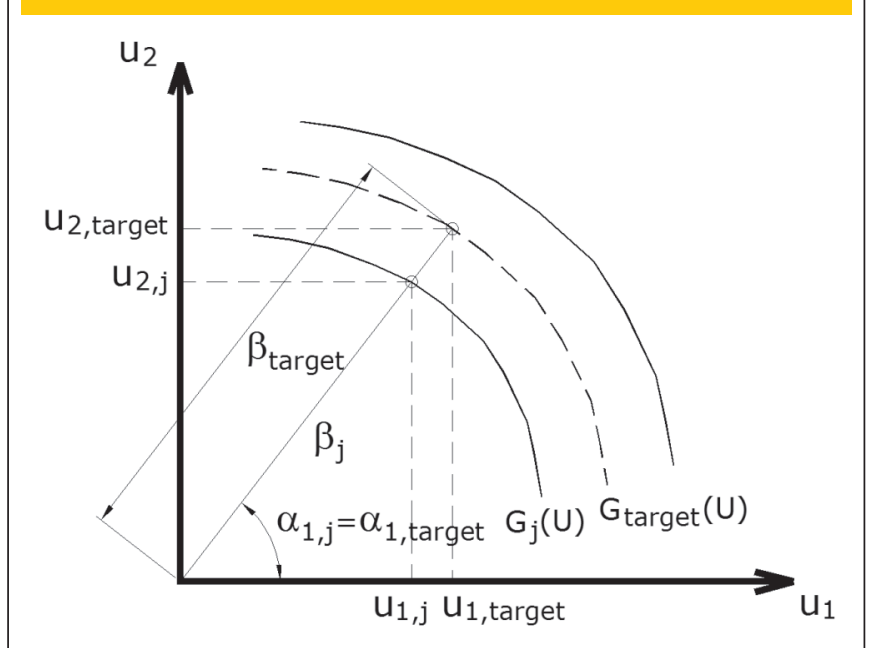

nates in physical space and reliability indices for $\beta_{x}=0,167$ in all load ratios.

Figure 6 illustrates the reliability indices of the beams designed with the new values of safety partial factors, considering all combinations between load ratios and the relative position of the neutral axis. As can be seen, the design of beams using the calibrated partial factors resulted in uniformity of the safety for the bending moment, achieving the target value of 3,8 specified for the ULS.

Figure 7 shows the safety partial factors for each load ratio, obtained by assessing the arithmetic mean between the values calibrated to the different relative positions of the neutral axis. The partial factors for the resistance of concrete and steel resulted slightly less than unity, meaning that the characteristic values are more pessimistic than the design values. The partial factor for the dead load ranged from $1,09(R=1,5)$ and $1,35(R=0,1)$, whereas for the live load, the variation was $1,18(R=0,1)$ to $2,64(R=1,5)$. As $R$ increases and, therefore, the importance of the live load increases, consequently, the value of its partial factor also increases. High

Table 3 - Results of the calibration process for $\beta_{x}=0,167$

\begin{tabular}{|cccccccccccc}
$\mathbf{R}$ & $\mathrm{f}_{\mathrm{c}}(\mathrm{MPa})$ & $\mathrm{f}_{\mathrm{y}}(\mathrm{MPa})$ & $\mathbf{M}_{\mathrm{g}}(\mathrm{kNcm})$ & $\mathbf{M}_{\mathrm{q}}(\mathrm{kNcm})$ & $\gamma_{\mathrm{c}}$ & $\gamma_{\mathrm{y}}$ & $\gamma_{\mathrm{g}}$ & $\gamma_{\mathrm{q}}$ & $\beta$ \\
0,1 & 23,2 & 485,6 & 6263,1 & 545,1 & 0,86 & 1,03 & 1,36 & 1,18 & 3,80 \\
0,3 & 23,6 & 504,3 & 4537,2 & 2424,9 & 0,85 & 0,99 & 1,22 & 2,18 & 3,78 \\
0,5 & 23,9 & 514,9 & 3413,6 & 3667,6 & 0,84 & 0,97 & 1,15 & 2,48 & 3,80 \\
0,7 & 24,0 & 519,4 & 2743,2 & 4377,9 & 0,83 & 0,96 & 1,13 & 2,57 & 3,80 \\
0,9 & 24,0 & 522,1 & 2293,3 & 4843,0 & 0,83 & 0,96 & 1,11 & 2,60 & 3,79 \\
1,1 & 24,1 & 523,8 & 1971,5 & 5186,4 & 0,83 & 0,95 & 1,10 & 2,63 & 3,80 \\
1,3 & 24,1 & 524,9 & 1728,8 & 5443,8 & 0,83 & 0,95 & 1,09 & 2,64 & 3,80 \\
1,5 & 24,1 & 525,7 & 1539,4 & 5644,1 & 0,83 & 0,95 & 1,09 & 2,65 & 3,80 \\
\hline
\end{tabular}




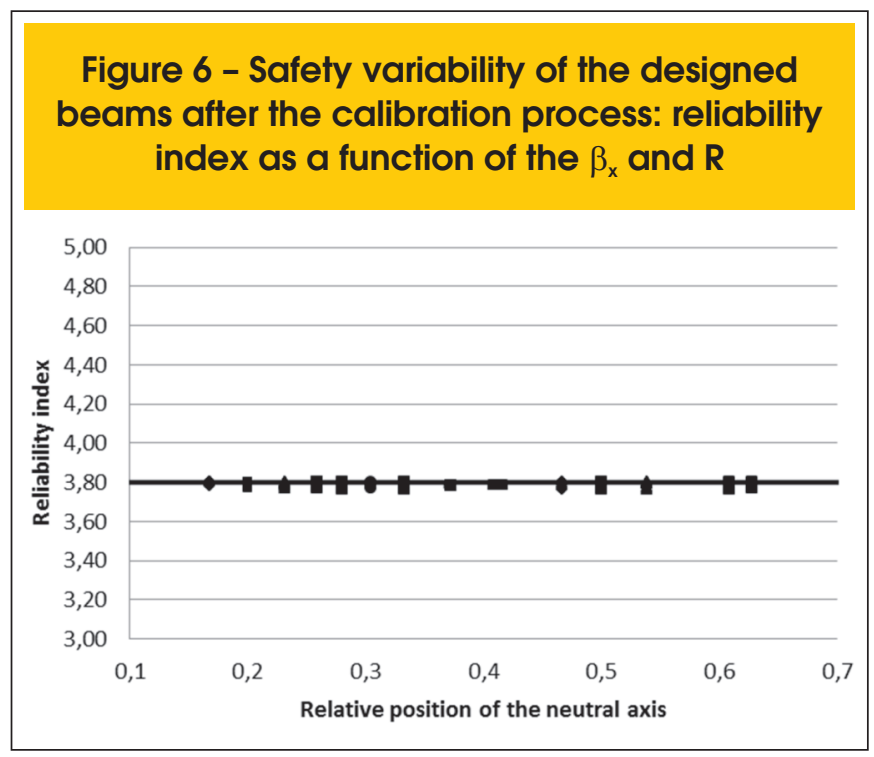

values above 2.00 reflect the greater uncertainty inherent in this variable when compared to the others.

Regarding to the sensitivity factors of the random variables, the same general behavior was observed when compared to prior calibration results, as can be seen in Figure 8 . The influence of concrete and steel strength variables is significantly sensitive to the relative position of neutral axis, alternating its importance as $\beta_{\mathrm{x}}$ increases. Since the parameters that depend on the dead and live loads, in which case are given by the bending moment, are more sensitive to variations in the load ratio than the neutral axis position.

The results showed that due to the calibration of safety partial factors of the resistances and active loads, it was possible to obtain uniformity in the safety of reinforced concrete beams subjected to bending moments. Thus, instead of using a single set of partial

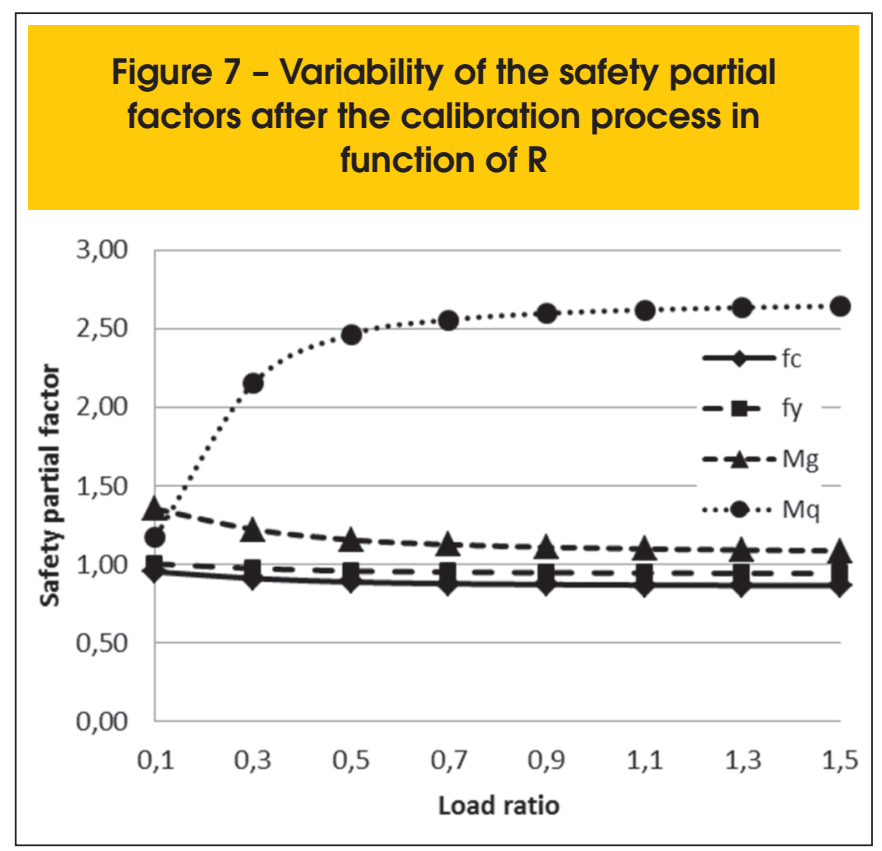

factors for all types of structures or design possibilities, a set of these coefficients are calibrated considering the particularities of each project, so that the desired safety level is actually achieved. The main disadvantage of this approach is not to present a fixed set of safety partial factors, which in principle can cause strangeness among design engineers. Moreover, the calibration of these coefficients requires knowledge, even if minimum, on statistical concepts and reliability theory. Such concepts are not easy-going and wide domain among professionals who work in the practice of the current structural engineering. However, the approach brings a major advantage: from the partial factor calibration process it is possible to specify and obtain the security level of the structural system according to the particular needs of each project. Thus, even if important parameters as the load ratios and the neutral axis are changed in design, the security obtained for the system remains the same.

Another important aspect that should be discussed is related to the possibility of obtaining a set of safety partial factors for the target reliability can be achieved. By varying each of the safety factors values for more or less, it is simply necessary to adjust the others parameters to keep the same reliability index, showing the various possibilities for adoption of the safety partial factors. Thus, the use of other criteria in addition with the calibration process is necessary to achieve the best partial factors, as for example, the solution with minimum cost regarding the designed configuration so that the optimal solution is reached. The minimum cost criterion in the calibration process was not considered in this paper.

\section{Proposal for a simplified design method}

Based on the results obtained with the safety partial factors calibration process, it was proposed a simplified alternative method for design reinforced concrete beams subjected to bending moment, whose steps are described below:

\section{Figure 8 - Variation on the random variables sensitivity regarding to failure probability of the beams after calibration}






\section{Figure 9 - Experiment plan to assess the coefficients of the polynomial for the random variables director cosines}

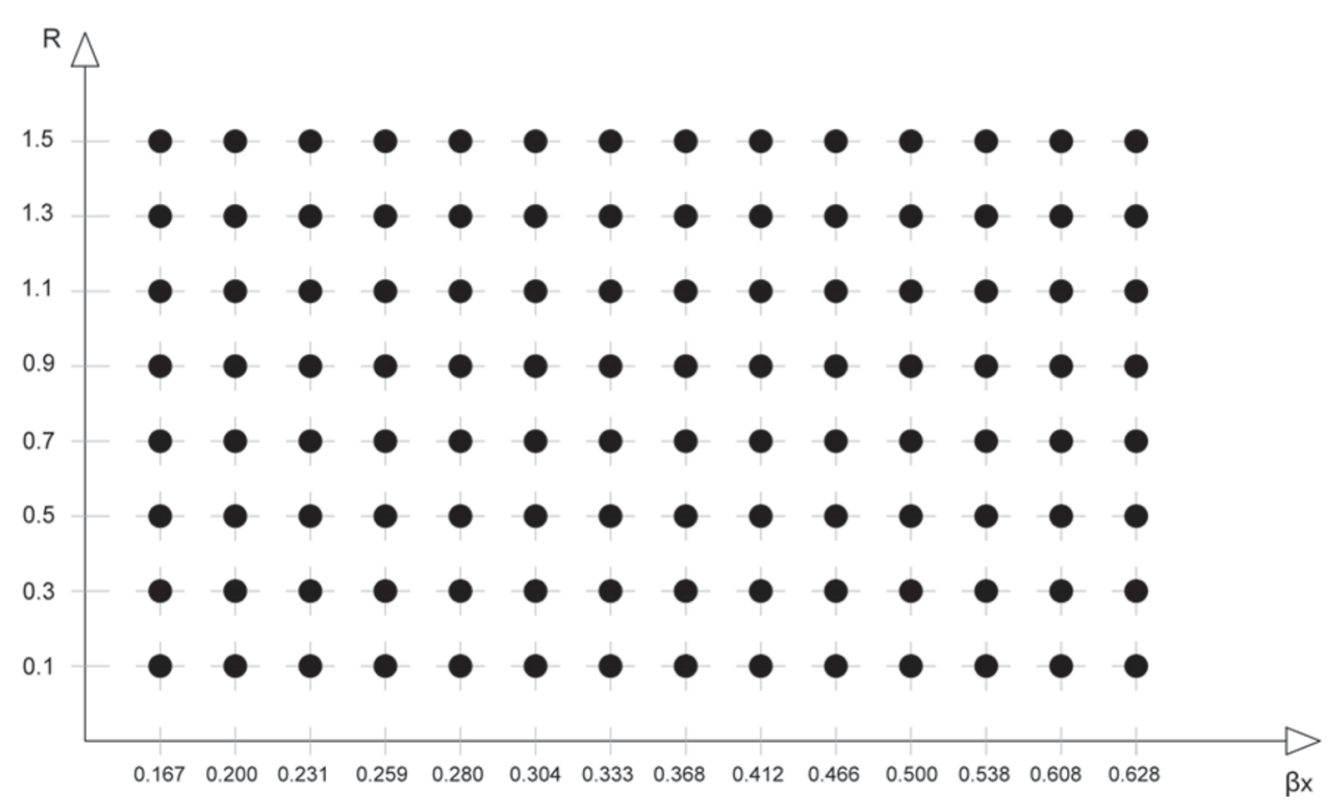

1. Select the desired security level, setting a value for the target reliability index;

2. Select the relative position of the neutral axis in the cross section for the ultimate limit state;

3. After the measurement of the loads on the beam, the load ratio $\mathrm{R}$ is assessed;

4. Evaluation of the cosines directors $\left(\alpha_{i}\right)$ for each random variable in the process, which in the case are: $f_{c}, f_{y}, M_{g}$ e $M_{q}$;

5. Evaluation of the safety partial factors of the variables from the Equations 21 and 22;

6. Designing of the cross section of the beam, obtaining the effective depth and tension reinforcement area.

The greatest difficulty in this process is to determine the cosine directors of the design variables. The most direct way is to conduct a reliability analysis via FORM, for example, to obtain these sensitivities from the statistics of the random variables. However, the use of this alternative would be quite restricted to the domain of strong computational tools for evaluating the structural reliability, preventing the application of this alternative design method. In order to overcome this problem, it was proposed an approximate way to get the cosine directors without the need to perform reliability analysis. As the relative position of the neutral axis and the load ratio are important parameters for the structural safety of the beams, a set of complete polynomials with $2^{\circ}$ and $4^{\circ}$ degrees for approaching each cosine director directly were adopted. Nogueira and Pinto [18] presented results of this procedure considering polynomials of $2^{\circ}$ degree and concluded that the final level of safety obtained oscillated around the value the reliability index target. The authors concluded that the $2^{\circ}$ degree polynomials were not sufficiently able to accurately represent the results of cosine directors obtained in reliability analysis. Furthermore, the study found values of $R$ be- tween 0.1 and 5.0 with non-constant variation, which increased the dispersion of the results, impairing the quality of the calibration. In general, the complete polynomials of $4^{\circ}$ degree considered can be written as:

$$
\begin{gathered}
\alpha_{i}=m_{0}+m_{1} \beta_{x}+m_{2} R+m_{3} \beta_{x}^{2}+m_{4} R^{2}+m_{5} \beta_{x} R+m_{6} \beta_{x}^{3} \\
+m_{7} R^{3}+m_{8} \beta_{x} R^{2}+m_{9} \beta_{x}^{2} R+m_{10} \beta_{x}^{2} R^{2}+m_{11} \beta_{x}^{4}+m_{12} R^{4} \\
+m_{13} \beta_{x} R^{3}+m_{14} \beta_{x}^{3} R+m_{15} \beta_{x}^{3} R^{3}+m_{16} \beta_{x}^{2} R^{3}+m_{17} \beta_{x}^{3} R^{2}
\end{gathered}
$$

Where: $m_{i}$ are the coefficients of the considered polynomial of cosines directors to be determined.

The least square method was used to determine the polynomials coefficients from the minimization of the error function given by:

$$
\text { erro }=\min \sum_{i=1}^{n p}\left[\alpha\left(\beta_{x}, R\right)_{i}-\alpha_{F O R M, i}\right]^{2}
$$

Where: $\alpha(\beta x, R)_{i}$ corresponds to the cosine director value of the variable considered for the point $i ; \alpha_{F O R M, i}$ is the value of the same cosine director, however from the original reliability analysis via FORM; $\mathrm{np}$ is the number of points of the considered experiment plan for the regression process. The solution algorithm of Equation (24) is described in details in Nogueira [19].

The experiment plan used to solve this problem was defined from all combinations considered among $\beta_{x}$ and $R$ in the process of the safety partial factors calibration, as illustrated in Figure 9. 
Thus, each point in the plane corresponding to the ordered pair $\beta_{x^{\prime}}$ $\mathrm{R}$ that generated a design beam and thus a set of values for the cosine directors of the random variables after reliability analysis. The Equations (25) (26) (27) and (28) bring the final polynomials for the cosine directors of the concrete compressive strength, steel strength, dead bending moment and live bending moment.

\begin{tabular}{|c|c|}
\hline $\begin{array}{c}\alpha_{\mathrm{fc}}=0,01068+0,89019 \beta_{\mathrm{x}}-0,14441 \mathrm{R}+0,91918 \beta_{\mathrm{x}}^{2}+0,39157 \mathrm{R}^{2} \\
-1,31285 \beta_{\mathrm{x}} \mathrm{R}-0,87883 \beta_{\mathrm{x}}^{3}-0,37175 \mathrm{R}^{3}+1,04762 \beta_{\mathrm{x}} \mathrm{R}^{2}-2,88967 \beta_{\mathrm{x}}^{2} \mathrm{R} \\
+3,26669 \beta_{\mathrm{x}}^{2} \mathrm{R}^{2}-0,05492 \beta_{\mathrm{x}}^{4}+0,11469 \mathrm{R}^{4}-0,28504 \beta_{\mathrm{x}} \mathrm{R}^{3}+3,76509 \beta_{\mathrm{x}}^{3} \mathrm{R} \\
+1,54548 \beta_{\mathrm{x}}^{3} \mathrm{R}^{3}-1,14201 \beta_{\mathrm{x}}^{2} \mathrm{R}^{3}-4,37646 \beta_{\mathrm{x}}^{3} \mathrm{R}^{2}\end{array}$ & (25) \\
\hline $\begin{array}{c}\alpha_{f y}=0,74758-0,18110 \beta_{x}-1,36333 R-0,76531 \beta_{x}^{2}+1,55151 R^{2}- \\
0,23677 \beta_{x} R+0,03935 \beta_{x}^{3}-0,81381 R^{3}+0,41170 \beta_{x} R^{2}+ \\
2,56287 \beta_{x}^{2} R-2,73007 \beta_{x}^{2} R^{2}+0,11055 \beta_{x}^{4}+0,15995 R^{4}-0,16771 \beta_{x} R^{3}- \\
0,80757 \beta_{x}^{3} R-0,30052 \beta_{x}^{3} R^{3}+0,92034 \beta_{x}^{2} R^{3}+0,87641 \beta_{x}^{3} R^{2}\end{array}$ & \\
\hline $\begin{array}{c}\alpha_{M g}=-0,98668-0,31458 \beta_{x}+2,77008 R+0,46710 \beta_{x}^{2}-3,62402 R^{2}+ \\
1,07523 \beta_{x} R+0,15813 \beta_{x}^{3}+2,21814 R^{3}-1,17569 \beta_{x} R^{2}-1,35814 \beta_{x}^{2} R+ \\
1,43383 \beta_{x}^{2} R^{2}+0,07304 \beta_{x}^{4}-0,51138 R^{4}+0,39650 \beta_{x} R^{3}-1,21408 \beta_{x}^{3} R- \\
0,52928 \beta_{x}^{3} R^{3}-0,47242 \beta_{x}^{2} R^{3}+1,47248 \beta_{x}^{3} R^{2}\end{array}$ & (27) \\
\hline $\begin{array}{c}\alpha_{M q}=0,26110-0,12803 \beta_{x}-5,70248 R+0,26403 \beta_{x}^{2}+9,71235 R^{2}+0,14988 \beta_{x} R- \\
0,06628 \beta_{x}^{3}-7,00452 R^{3}-0,05158 \beta_{x} R^{2}-0,99148 \beta_{x}^{2} R+1,11111 \beta_{x}^{2} R^{2}- \\
0,01497 \beta_{x}^{4}+1,80209 R^{4}-0,00353 \beta_{x} R^{3}+1,58695 \beta_{x}^{3} R+0,86056 \beta_{x}^{3} R^{3}- \\
0,38191 \beta_{x}^{2} R^{3}-2,25027 \beta_{x}^{3} R^{2}\end{array}$ & (28) \\
\hline
\end{tabular}

Figures 10 to 13 illustrate the accuracy of the $4^{\circ}$ degree polynomial to obtain the cosine directors, compared to the solutions given by Nogueira and Pinto [18] with a $2^{\circ}$ degree polynomial and the FORM. With that, during the design of the beams with the proposed method, it is sufficient to calculate the values of the cosine directors by Equations (25) to (28) without the need for auxiliary reliability analysis.

\section{Calculation example}

To demonstrate the application of the simplified method proposed in this study, a reinforced concrete beam was designed to bending moment, varying the use of the structure and consequently

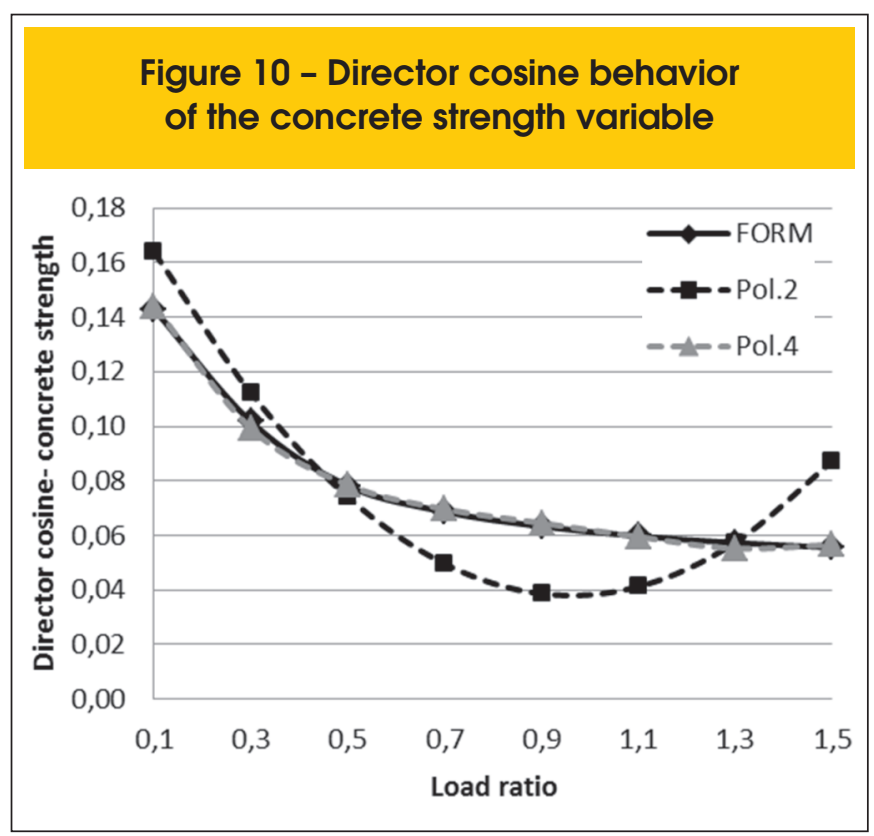

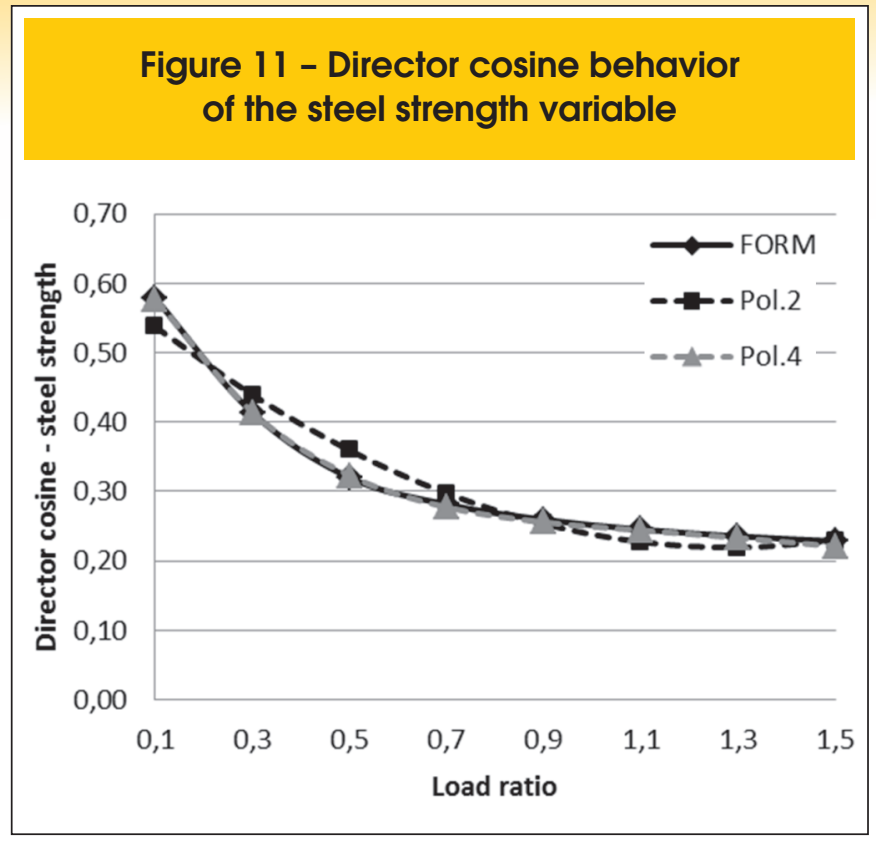

the load ratio. Figure 14 shows the characteristics of the fictitious pavement considered as well as the beam V2 chosen for design. The dead loads were estimated considering: reinforced concrete solid slab with a thickness of $10 \mathrm{~cm}$; regularization on the slab of cement and sand mortar with a thickness of $2 \mathrm{~cm}$; ceramic floor on the regularization with specific weight of $18 \mathrm{kN} /$ $\mathrm{m}^{3}$ and a thickness of $6 \mathrm{~mm}$; coated liner on the bottom of the slab composed of cement and sand mortar with a thickness of 1 $\mathrm{cm}$. All values of the specific weights of the materials were obtained from NBR 6120 [21]. The total dead load on the slab was $3,24 \mathrm{kN} / \mathrm{m}^{2}$, which resulted in uniformly distributed dead load $(\mathrm{g})$ transmitted to the beam V2 with $16,2 \mathrm{kN} / \mathrm{m}$. Regarding the live load (q) considered over the entire slab, the recommended values have been adopted by the NBR 6120 [21] according to the building functionality. Thus, the following legend was adopted: A - terraces or liners without people access; B - bedrooms, living room, kitchen and bath; $C$ - pantry, laundry area and laundry room; D - reading room in libraries; E - garages for common vehicles; F - stadium bleachers; G - dance hall and gymna-

\section{Figure 12 - Director cosine behavior of the dead bending moment variable}

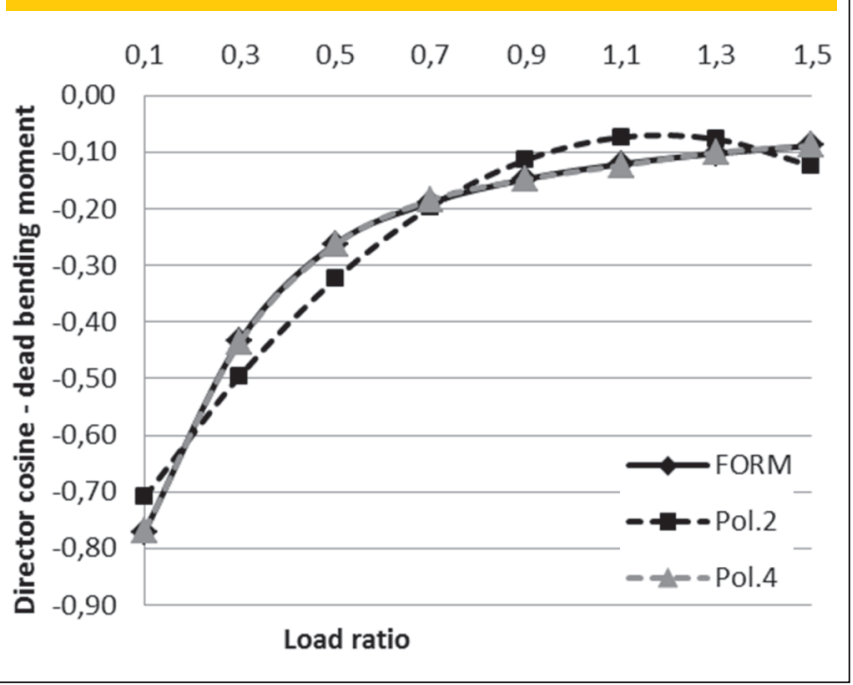




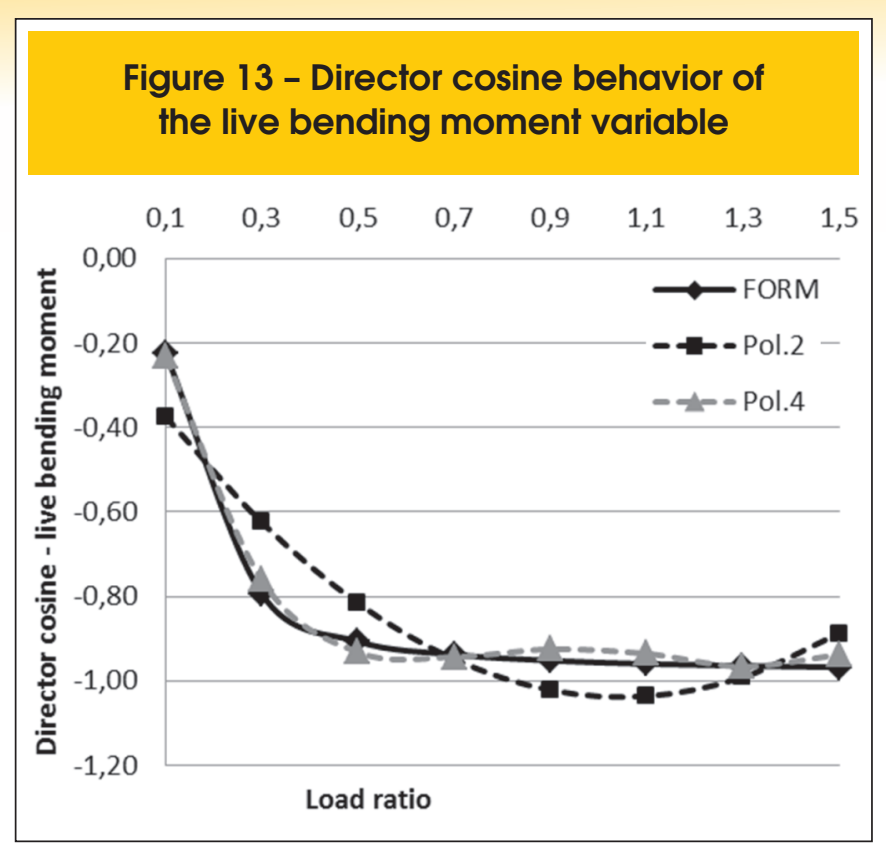

sium. These nomenclatures are placed in the "Type" column in Table 4.

For comparative purposes, the beams were designed considering the conventional safety partial factors of NBR 6118 [13] and then considering the calibrated partial factors in accordance with the proposed process. The width of the beam was kept constant at the value of $14 \mathrm{~cm}$ and the characteristics resistance of concrete and steel was adopted, respectively, in the amounts of $20 \mathrm{MPa}$ and $500 \mathrm{MPa}$. The safety factors were calibrated to reliability index target of 3,8 . In all cases the relative position of the neutral axis at ULS was adopted and kept constant at 0,45 for that the ductility constraint imposed by the NBR 6118 [13] always have been respected. Table 4 gathers the results of this analysis. As can be seen, the major differences between the two calculation methods are for low values of the load ratio. This shows that in situations where live loads are significantly smaller than the dead loads, the partial factors used by NBR 6118 [13] lead to excessively secure design. This behavior changes as $R$ increases, where the security level of the beams tends to decrease, violating the limit of 3,8 proposed by Eurocode 2 [20]. Thus, the lack of uniformity in the beams security is evident. Moreover, when calibrating the partial factors according to the project need, it is possible to obtain uniformity of structural safety, as the reliability index values obtained in the analysis. The $\beta_{\text {medium }}$ obtained with the proposed method was 3,80 while for the model of NBR 6118 [13] was 4,50, which demonstrates once again that the proposed calibration procedure allows, besides reaching the target security level specified in the design, ensure uniformity of structural safety.

\section{Conclusions}

In this article it was presented a study about the safety of reinforced concrete beams designed to bending moment, considering the set of partial factors for resistance of the materials (steel and concrete) and the action effects (permanent and variable bending moments) through the reliability theory. After the performed analyzes, the following conclusions were highlighted:

Figure 14 - Considered floor in the analysis: dimensions in centimeter

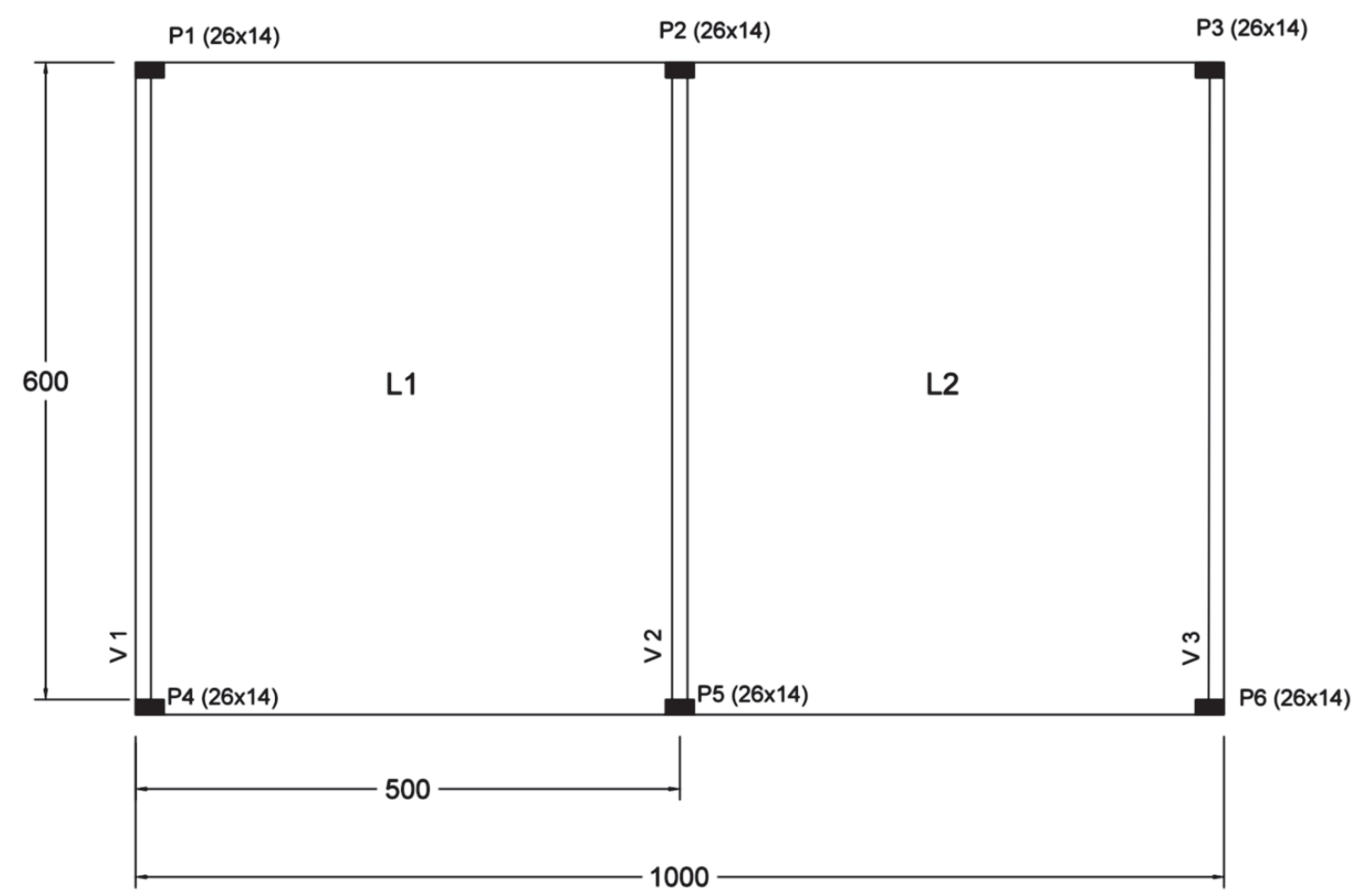




\section{Table 4 - Design of the beams considering the set of calibrated safety factors and the standard ones}

\begin{tabular}{|c|c|c|c|c|c|c|c|c|}
\hline \multirow[b]{2}{*}{ Type } & \multirow[b]{2}{*}{$q\left(k N / m^{2}\right)$} & \multirow[b]{2}{*}{$\mathbf{R}$} & \multicolumn{3}{|c|}{ Proposed method } & \multicolumn{3}{|c|}{ NBR 6118} \\
\hline & & & $\mathrm{d}(\mathrm{cm})$ & $A_{s}\left(\mathrm{~cm}^{2}\right)$ & $\beta$ & $\mathrm{d}(\mathrm{cm})$ & $A_{s}\left(\mathrm{~cm}^{2}\right)$ & $\beta$ \\
\hline A & 0,5 & 0,14 & 40,15 & 7,01 & 3,70 & 49,50 & 6,97 & 6,51 \\
\hline B & 1,5 & 0,42 & 46,84 & 8,43 & 3,86 & 55,20 & 7,77 & 4,92 \\
\hline C & 2,0 & 0,56 & 50,44 & 9,16 & 3,90 & 57,85 & 8,14 & 4,51 \\
\hline$D$ & 2,5 & 0,70 & 53,43 & 9,75 & 3,83 & 60,39 & 8,50 & 4,24 \\
\hline$E$ & 3,0 & 0,84 & 56,13 & 10,27 & 3,75 & 62,82 & 8,84 & 4,03 \\
\hline $\mathrm{F}$ & 4,0 & 1,11 & 62,06 & 11,38 & 3,77 & 67,41 & 9,49 & 3,75 \\
\hline$G$ & 5,0 & 1,39 & 68,31 & 12,55 & 3,88 & 71,72 & 10,09 & 3,56 \\
\hline
\end{tabular}

It has been found, indeed, the lack of uniformity in the safety of the beams subjected to bending moment when they are always designed with the same values of safety partial factors for different situations of the neutral axis position and load ratios. Using the same safety partial factors values does not take into account the influence of the neutral axis position and the ratio of the effects produced by the dead and live loads on the behavior of the beams. Thus, for low values of $R$, the security level obtained is too high, while for high values of $R$, the level decreases, resulting in situations against security;

- The proposed calibration process of the safety based on the results of reliability analysis was stable and capable of ensuring the reliability index target for beams designed with the new partial factors. Polynomials with degree of 4 to calculate the cosine directors of the project variables were adequate, because they allowed the design method was applied without the need for new reliability analysis, achieving good results. Thus, the uniformity was guaranteed in the safety of the beams subjected to bending moment;

- Therefore, instead of using a fixed set of safety partial factors, the method proposes the adoption of the security level required in the project through the reliability index or failure probability for the considered limit state and, from that information, calibrate the partial factors to achieve this level of safety;

- It is worth to note that, there are several of possible combinations to partial factors that result in the same values of reliability index. Thus, it is necessary to quantify the costs of the beams construction designed with new safety factors, compare them with the costs obtained with the standard process and assess what the optimal set of factors ensures the required safety, reflecting the lower cost to the structure. This cost analysis was not performed in this work and is currently under development.

\section{Acknowledgements}

The authors would like to acknowledge UNESP - FEB for the support in the research development.

\section{References}

[1] ELLINGWOOD, B.; GALAMBOS, T.V. Probability-based criteria for structural design. Structural Safety, v.1, 1982; p.15-26.

[2] ELLINGWOOD, B. LRFD: implementing structural reliability in professional practice. Engineering Structures, v.22, 2000; p.106-115.

[3] SØRENSEN, J.D.; KROON, I.B.; FABER, M.H. Optimal reliability-based code calibration. Structural Safety, v.15, 1994, p.197-208.

[4] NOWAK, A.S.; COLLINS, K.R. Reliability of structures. Michigan: McGraw-Hill, 2000, 338 p.

[5] MADSEN, H.O.; KRENK, S.; LIND, N.C. Methods of structural safety. Prentice-Hall, Englewood Cliffs, N.J., 1986.

[6] HAN, B.K. Reliability assessment and design load factors for reinforced concrete containment structures. Reliability Engineering and System Safety, v.62, 1998, p.235-240.

[7] FREUDENTHAL, A.M. The safety of structures. Transactions of ASCE, v.112, 1947, p.125-180.

[8] KOGUT, G.F.; CHOU, K.C. Partial resistance factor design on steel-concrete beam-columns. Engineering Structures, v.26, 2004, p.857-866.

[9] MOHAMED, A.; SOARES, R.; VENTURINI, W.S. Partial safety factors for homogeneous reliability of nonlinear reinforced concrete columns. Structural Safety, v.23, 2001, p. 137-156.

[10] CASTILLO, E.; CONEJO, A.J.; MÍNGUEZ, R.; CASTILLO, C. An alternative approach for addressing the failure probability-safety factor method with sensitivity analysis. Reliability Engineering and System Safety, v.82, 2003, p.207-216.

[11] GAYTON, N.; MOHAMED, A.; SORENSEN, J.D.; PENDOLA, M.; LEMAIRE, M. Calibration methods for reliabilitybased design codes. Structural Safety, v.26, 2004, p.91-121.

[12] STUCCHI, F.R.; SANTOS, S.H.C. Reliability based comparison between ACI 318-05 and NBR 6118. IBRACON Structural Journal, v.3, n.2, June, 2007, p.230-239.

[13] BRAZILIAN ASSOCIATION OF TECHNICAL STANDARDS (ABNT). Design of concrete structures - procedures (NBR 6118), Rio de Janeiro, 2014, 238 p. (in Portuguese) 
[14] ACI COMMITTEE 318, Building code requirements for structural concrete ( $\mathrm{ACl} 318-05)$ and commentary (318R-05), American Concrete Institute, Farmington Hills, Michigan, 2005, $430 \mathrm{p}$.

[15] BECK, A.T.; SOUZA JR, A.C. A first attempt towards reliability-based calibration of Brazilian structural design codes. J. of the Braz. Soc. Of Mech. Sci. \& Eng. v.XXXII, n.2, April-June, 2010, p.119-127.

[16] BRAZILIAN ASSOCIATION OF TECHNICAL STANDARDS (ABNT). Design of steel and steel-concrete composite structures: procedures (NBR 8800), Rio de Janeiro, 2008. (in Portuguese)

[17] ANSI/AISC 360. Specification for structural steel buildings. American Institute of Steel Construction, Chicago, Illinois, 2005.

[18] NOGUEIRA, C.G.; PINTO, M.D.T. Análise de confiabilidade de vigas em concreto armado segundo a ABNT NBR 6118: avaliação da segurança e calibração dos coeficientes parciais de segurança. In: $56^{\circ}$ Congresso Brasileiro do Concreto, Natal, 2014, Anais, Rio Grande do Norte, 2014.

[19] NOGUEIRA, C.G. Desenvolvimento de modelos mecânicos, de confiabilidade e de otimização para aplicação em estruturas de concreto armado. Tese de Doutorado, Escola de Engenharia de São Carlos, Universidade de São Paulo, 2010.

[20] EUROCODE 2. Design of concrete structures. Part 1: general rules and rules for buildings. Brussels: CEN, 1989.

[21] BRAZILIAN ASSOCIATION OF TECHNICAL STANDARDS (ABNT). Loads for building structures design (NBR 6120), Rio de Janeiro, 1980. (in Portuguese). 